\title{
DESENVOLVIMENTO DA IDENTIDADE VISUAL DO INSTITUTO DE ENSINO E PESQUISA RICO VIVER
}

\section{Ana Flávia Rocha de Oliveira ${ }^{1}$ \\ Celeste Marinho Manzanett ${ }^{2}$}

Resumo: O presente artigo tem como tema o desenvolvimento da identidade visual de uma organização não governamental, para que esta ganhe visibilidade no mercado, além tornar-se a representação da identidade da marca, diretamente ligada à essência do serviço oferecido. A metodologia utilizada baseia-se em pesquisas qualitativas, sendo estas: pesquisas com perguntas abertas, aplicadas em profissionais que trabalham com a equinoterapia, familiar de um praticante da equoterapia e com o fundador da Organização, Henrique de Almeida Basano, pesquisa documental, baseada principalmente em artigos, um método que trás um estudo ainda mais atualizado e pesquisa bibliográfica, buscando a teoria em livros que permite uma análise profunda sobre cada assunto. O estudo tem o intuito de reforçar no mercado a imagem de uma organização não governamental que visa a inclusão social, gerando o crescimento de toda a sociedade.

Palavras-chave: Identidade visual; ONG; Equoterapia; Equinoterapia.

\footnotetext{
${ }^{1}$ Comunicação Social aplicada/Universidade do Vale do Paraíba, Brasil. E-mail: ana_flavia_1994@hotmail.com.

2 Comunicação Social aplicada/Universidade do Vale do Paraíba, Brasil. E-mail: celestemanza@gmail.com.
} 